\title{
Effectiveness of Ultrasound Therapy on the Management of Chronic Non-Specific Low Back Pain: A Systematic Review
}

\author{
Gebremedhin Haile \\ Teklehaimanot Tekle \\ Hailemariam (iD) \\ Tsiwaye Gebreyesus Haile iD \\ Department of Physiotherapy, School of \\ Medicine, College of Health Sciences and \\ Ayder Comprehensive Specialized \\ Hospital, Mekelle University, Mekelle, \\ Ethiopia
}

\begin{abstract}
Non-specific chronic low back pain is the most common self-reported kind of musculoskeletal ache associated with substantial health and socioeconomic problem and responsible for most years lived with a disability as compared with any other medical condition. So treating chronic non-specific low back pain is one of the main problems faced among physical therapists in the rehabilitation area. The effects of ultrasound for patients with non-specific chronic low back pain remain unknown, however it is commonly used to treat clients with low back pain in rehabilitation setting. Therefore, the main aim of this review was to evaluate the up-to-date confirmation in the efficacy of ultrasound therapy on the treatment of non-specific chronic low back pain. A comprehensive search of four computerized electronic databases was performed to identify the effectiveness of ultrasound therapy on the management of chronic non-specific low back pain. Searching was done through the Google Scholar, PubMed, ScienceDirect, and Physiotherapy Evidence Databases (PEDro) and reported using preferred reporting items for systematic reviews and meta-analyses guidelines. The qualities of articles were appraised by the PEDro scale. The primary outcome measure visual analog scale was used. Six randomized clinical trials with a total sample size of 699 patients from the electronic database published in English were identified. In this review, the effect of UST in five articles was statically significant in reducing the visual analog scale $(p<0.05)$ score. So this systematic review found ultrasound therapy could be an alternative treatment to reduce the intensity of pain in subjects with non-specific chronic LBP.
\end{abstract}

Keywords: back pain, biophysical agents, effectiveness, low back pain, rehabilitation and ultrasound therapy

\section{Introduction}

Low back pain (LBP) can be defined as an ache and discomfort below the 12th rib of the lumbar spine and above the gluteal fold. According to the suggested diagnostic triage, there are three forms of LBP. Those are non-specific LBP, LBP with nerve root symptoms, LBP resulting from serious pathology (eg malignancy, fracture, ankylosing spondylitis). Non-specific LBP can define as if there is no known pathoanatomical cause and frequently benign with a self-limiting condition.

LBP is also categorized based on its duration as acute (less than 6 weeks), subacute (6 to 12 weeks), and chronic (greater than 12 week). ${ }^{15}$

Low back pain (LBP) is the most common self-reported kind of musculoskeletal ache. It is frequently recurrent and had burdened on socioeconomic. The prevalence 
of LBP differs significantly between studies and reaches $33 \%$ for point prevalence, $65 \%$ for one-year prevalence, and $84 \%$ for lifetime prevalence. Chronic non-specific low back pain (CNSLBP) and its resulting infirmity have become a huge health and socioeconomic burden. ${ }^{4}$ LBP is reportedly associated with decreased activities of daily living and quality of life. ${ }^{12}$

Electrotherapy is modalities like interferential current therapy, transcutaneous electrical nerve stimulation, and high voltage are effective in treating chronic $\mathrm{LBP}^{24}$ In physiotherapy next to manual therapy and exercises, electrotherapy modalities are widely used to decrease pain. Among them, the best-known modalities are transcutaneous electrical nerve stimulation and interferential current therapy. 9,29,32 There were positive results in chronic LBP improvement both with transcutaneous electrical nerve stimulation and interferential current, without significant difference between transcutaneous currents. ${ }^{9,29}$ Modalities like low-level laser therapy; magnetic therapy, and shock wave therapy significantly reduce pain symptoms and leads to an improvement of functional ability in patients with LBP. ${ }^{13,28,30}$ However, there is still a lack of evidence supporting its effect on improving functional activities. ${ }^{13}$

Ultrasound therapy (UST) is often used by physical therapy in the management of LBP and is almost surely the most commonly used electro-physical agent in current clinical practice. ${ }^{3}$ Ultrasound therapies is one of the most common electro physical agents which commonly used in the management of LBP in the clinical practice by physical therapist professions. It is also frequently used for the management of musculoskeletal conditions by other health professionals such as osteopaths, chiropractors, and sports therapists. The assumption is that ultrasound therapy delivers energy to deep tissue sites through ultrasonic waves, to produce increases in tissue temperature or non-thermal physiologic changes. ${ }^{2}$

Ultrasound therapy can be provided in two modes, continuous or pulsed. Continuous ultrasound includes the delivery of non-stop ultrasonic waves throughout the treatment period; while in pulsed ultrasound, the delivery is intermittently interrupted. ${ }^{25}$ Ultrasound for medical imaging which transmits ultrasonic waves and processes a returning echo to generate an image) however, ultrasound therapy is a one-way energy delivery which uses a crystal sound head to transmit acoustic waves at 1 or $3 \mathrm{MHz}$ and amplitude densities between 0.1 watts $/ \mathrm{cm} 2$ and 3 watts $/ \mathrm{cm} 2$. $^{2,25}$
In most studies, the effect of ultrasound therapy was compared with other modalities, ${ }^{7,22}$ or is presented in a package of physiotherapy. ${ }^{6}$ The efficacy of therapeutic ultrasound for musculoskeletal conditions remains not constant. $^{26}$ There is also a lack of proof for clinical use in patients with chronic low back pain. ${ }^{14}$ This systematic review was aimed to assess the efficacy of ultrasound therapy in the treatment of patients with CNSLBP. Therefore, this review provides additional current evidence on the efficacy of therapeutic ultrasound on patients with CNSLBP focusing on too early published studies.

\section{Methods}

\section{Design and Protocol Registration}

This systematic review was showed and reported following the preferred reporting items for systematic reviews and meta-analyses (PRISMA). ${ }^{20}$

\section{Search Strategy}

Searching articles were done that published from 2005 to august 2020 and conducted on PubMed, Google Scholar, ScienceDirect, and PEDro databases. By taking an article that is similar to some reference. The following keywords "ultrasound or ultrasound therapy", "back pain and RCT were used.

\section{Eligibility Criteria}

Studies were considered as eligible if met the criteria as follows: All adult patients with CNSLBP were included. It is also all adult men and women were included. Only randomized controlled clinical trials (RCTs) assessing the effect of UST on CNSLBP were included. The intervention groups received UST modalities included. The primary outcome measure visual analog scale (VAS) was used included. Only full articles available, published in English were selected. RCT Studies display abstract only were excluded. Studies of post-operative patients and patients in whom a specific cause for their LBP had been determined were excluded. Observational studies and quasi-experimental studies were excluded from this review.

\section{Study Selection}

One review $(\mathrm{GH})$ is the initial response for the selection of the studies and the studies were retrieved in detail through methodological quality and data extraction tools by two reviewers ( $\mathrm{GH}$ and $\mathrm{TT}$ ). The third reviewer (TG)) was 
solved the difference between the two reviewers. All authors revised and approved the final manuscript.

\section{Methodological Quality Assessment}

After searching articles that were relevant to this literature review the quality was assessed by two reviewers. The reviewers evaluated the quality of the included studies based upon the Physiotherapy Evidence Database (PEDro) Scale scored using ten items but the 1st item only indicates the external validity of (applicability of the trial) the article not included in the score. ${ }^{5,19}$ Finally the overall quality of the studies was also ranked using the GRADE approach. ${ }^{11}$ The GRADE approach is categorized into high, moderate, low, and very low. Accordingly, the PEDro score of the six included articles score ranges from 6-9. In all studies, randomization and assessors blinding were carried $100 \%$ but no blinding for therapists was found. See Table 1

\section{Results}

\section{Study Selection}

The searching strategy that fulfills the criteria for inclusion six articles were identified and 24 full-text articles were excluded. Our selection process of the studies was displayed in Figure 1

\section{Data Extraction}

The reviewers were prepared the tools and pull out the data. Those data were pulled out from each study; the number of participants in both groups, follow-up time, frequency of treatments, kind of treatment and mean age of the participants, outcome measures, study results, and conclusions.

\section{Study Characteristics}

A total of 699 patients with CNSLBP their age running from 31 to 56 years old were included. The overall descriptions of characteristics for the included six trials displayed in Table 2

\section{Intervention for LBP}

In this review, the included sample sizes were running from 30 to 445 participants, and its treatment durations 3 wks to 6 months. In this systematic review, six randomized clinical trials were included that assessed the effectiveness of ultrasound therapy on CNSLBP. In each of those studies, therapeutic ultrasound was found to be more effective than a dummy in reducing pain. ${ }^{7,10,22,27}$ However, in one study UST was not effective when compared to placebo. ${ }^{18}$ No study reported adverse effects.

Durmus et $\mathrm{al}^{7}$ reviewed the efficacy of ultrasound therapy in the management of CNSLBP. These authors enough information stated which support the use of ultrasound therapy in the decrease of pain, increase muscle strength and quality of life. Also, three studies reviewed these Mohseni-Bandpei et al, Fiore et al, and Tantawy et $\mathrm{al}^{10,22,27}$ the efficacy of therapeutic ultrasound therapy in the management of CNSLBP. These studies reported enough evidence which supports the use of ultrasound therapy in decreasing pain, disability, and increase range of motion.

Table I PEDro Score for Each Studies

\begin{tabular}{|c|c|c|c|c|c|c|}
\hline PEDro Items & $\begin{array}{l}\text { Durmus et al } \\
(2010)^{7}\end{array}$ & $\begin{array}{l}\text { Mohseni-Bandpei } \\
\text { et al }(2006)^{22}\end{array}$ & $\begin{array}{l}\text { Tantawy et al } \\
(2018)^{27}\end{array}$ & $\begin{array}{l}\text { Ebadi et al } \\
(20 \mid 2)^{8}\end{array}$ & $\begin{array}{l}\text { Fiore et al } \\
(2011)^{10}\end{array}$ & $\begin{array}{l}\text { Licciardone } \\
\text { et al }(20 \mid 3)^{18}\end{array}$ \\
\hline Eligibility & No & Yes & Yes & Yes & Yes & Yes \\
\hline Random allocation & Yes & Yes & Yes & Yes & Yes & Yes \\
\hline Concealed allocation & No & No & Yes & Yes & Yes & Yes \\
\hline Base line comparability & Yes & Yes & Yes & Yes & Yes & Yes \\
\hline Blind participants & Yes & No & No & Yes & No & Yes \\
\hline Blind therapist & No & No & No & No & No & No \\
\hline Blind assessor & Yes & Yes & Yes & Yes & Yes & Yes \\
\hline Adequate follow-up & No & Yes & Yes & No & Yes & Yes \\
\hline Intention to treat analysis & No & No & No & Yes & Yes & Yes \\
\hline Between-group comparisons & Yes & Yes & Yes & Yes & Yes & Yes \\
\hline Point estimates and variability & Yes & Yes & Yes & Yes & Yes & Yes \\
\hline PEDro score & $6 / 10$ & $6 / 10$ & $7 / 10$ & $8 / 10$ & $8 / 10$ & $9 / 10$ \\
\hline Type of RCT quality & Moderate & Moderate & High & High & High & High \\
\hline
\end{tabular}




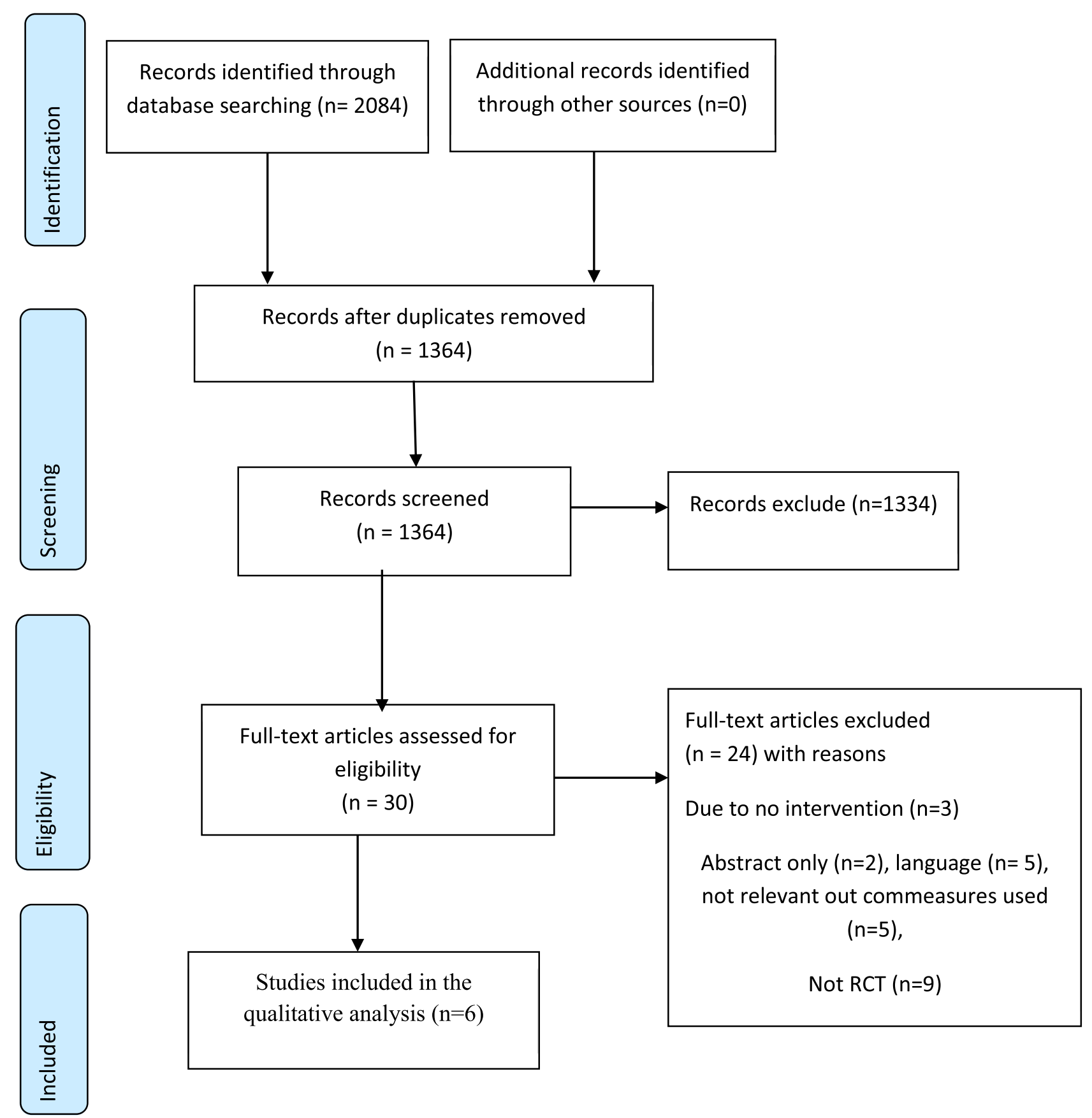

Figure I Flow diagram of selection of studies using preferred reporting items for systematic reviews and meta-analyses (PRISMA).

Notes: Modified from Moher D, Liberati A, Tetzlaff J, Altman DG, The PRISMA Group (2009) Preferred Reporting Items for Systematic Reviews and Meta-Analyses: The PRISMA Statement. PLoS med. 2009;6(7):el000097. Copyright: (C) 2009 Moher et al Creative Commons Attribution License. ${ }^{21}$

A study conducted in Iran by Ebadi et $\mathrm{al}^{8}$ assessed the effectiveness of UST and placebo UST plus semisupervised exercise on a patient with CNSLBP. After the treatment session, the mean VAS score drops out on both groups and vary with time. Both group analyses showed that VAS scores improved significantly from baseline to after the 10th session $(\mathrm{p}<0.001)$ and continued to improve until the one-month follow-up measurement $(p=0.004)$. In this study for CNSLBP apply UST the same improvement being applied placebo UST plus semisupervised exercise. Another study was done by Licciardone et $\mathrm{al}^{18}$ determined the effectiveness of UST on CNSLBP. However, at the end of the treatments, the analysis did not showed signify cant reductions in pain scores on the visual analog scale overtime when UST compared with sham UST $(\mathrm{P}=0.99)$. So the author 
Table 2 The Characteristics of the Six Studies

\begin{tabular}{|c|c|c|c|c|c|c|}
\hline $\begin{array}{l}\text { Author } \\
\text { (Year) }\end{array}$ & $\begin{array}{l}\text { Ebadi et al } \\
(20 \mid 2)^{8}\end{array}$ & $\begin{array}{l}\text { Durmus et al } \\
(2010)^{7}\end{array}$ & $\begin{array}{l}\text { Mohseni- } \\
\text { Bandpei et al } \\
(2006)^{22}\end{array}$ & $\begin{array}{l}\text { Licciardone } \\
\text { et al }(2013)^{18}\end{array}$ & $\begin{array}{l}\text { Fiore et al } \\
(20 \mathrm{II})^{10}\end{array}$ & $\begin{array}{l}\text { Tantway et al } \\
(2018)^{27}\end{array}$ \\
\hline $\begin{array}{l}\text { Types of } \\
\text { study }\end{array}$ & RCT & $\mathrm{RCT}$ & RCT & RCT & RCT & RCT \\
\hline $\begin{array}{l}\mathrm{N} \\
\text { Mean age } \pm \\
\mathrm{SD}\end{array}$ & $\begin{array}{l}N=50 \\
(G I=25 \\
G 2=25), \\
G I=3 I .4 \pm I 2.3 \\
G 2=37.4 \pm I I .9\end{array}$ & $\begin{array}{l}N=59 \\
(G I=20 \\
G 2=19 \\
G 3=20) \\
G I=49.00 \pm, 7.87 \\
G 2=48.31 \pm 8.95 \\
G 3=47.05 \pm 12.46\end{array}$ & $\begin{array}{l}N=60 \\
(G I=60 \\
G 2=60), \\
G I=34.8 y(10.6) \\
G 2=37.2 y(10.2\end{array}$ & $\begin{array}{l}N=455 \\
(G I=230 \\
G 2=225)\end{array}$ & $\begin{array}{l}N=30 \\
G I=I 5 \\
G 2=I 5 \\
G|\& G 2=5| .2 \\
\pm 6\end{array}$ & $\begin{array}{l}N=45 \\
(G \mid=I 5 \\
G 2=15 \\
G 3=\mid 5) \\
G I=37.03 \pm 6.74 \\
G 2=36.32 \pm 7.82 \\
G 3=36.85 \pm 7.14\end{array}$ \\
\hline PEDro score & $8 / 10$ & $6 / 10$ & $6 / 10$ & $9 / 10$ & $8 / 10$ & $7 / 10$ \\
\hline $\begin{array}{l}\text { Out } \\
\text { commeasures }\end{array}$ & VAS & VAS, FRI & VAS,OLBPD & VAS & $\begin{array}{l}\text { VAS, } \\
\text { OLBPDQ }\end{array}$ & VAS,OLBPDQ, \\
\hline Intervention & $\begin{array}{l}\text { UST (I MHz \&I.5 } \\
\left.\text { W/ } \mathrm{cm}^{2}\right) \text { plus } \\
\text { exercise (TG) and } \\
\text { placebo UST plus } \\
\text { exercise (CG) }\end{array}$ & $\begin{array}{l}\text { UST (IMHz and I w/ } \\
\mathrm{cm}^{2} \text { ) plus exercise } \\
\text { (TGI), ES plus exercise } \\
\text { (TG2), and only } \\
\text { exercise (CG) }\end{array}$ & $\begin{array}{l}\text { UST }(\mathrm{IMHz} 1.5 \\
\text { and } 2.5 \mathrm{~W} / \mathrm{cm} 2 \\
\text { plus exercise and } \\
\text { manipulation plus } \\
\text { exercise }\end{array}$ & $\begin{array}{l}\text { UST(TGI) or } \\
\text { sham UST(CG) } \\
\text { and OMT } \\
\text { (TG2) or sham } \\
\text { OMT(CG) }\end{array}$ & $\begin{array}{l}\text { UST (GI) } \\
\text { and HILT } \\
(\mathrm{G} 2)\end{array}$ & $\begin{array}{l}\text { UST ( } \mathrm{I} \mathrm{MHz} \text {, and I } \\
\mathrm{W} / \mathrm{cm}^{2} \text { plus exercise } \\
\text { (TGI), PBT plus } \\
\text { exercise(TG2) and } \\
\text { exercise (CG) }\end{array}$ \\
\hline $\begin{array}{l}\text { Frequency } \\
\text { and Follow- } \\
\text { up time }\end{array}$ & 3 days/wk. for 4 wks & 3 days/wk. for 3wks & $\begin{array}{l}6 \text { treatment } \\
\text { session follow for } \\
6 \text { months }\end{array}$ & $\begin{array}{l}6 \text { treatment } \\
\text { sessions follow } \\
\text { for } 8 \text { wks. }\end{array}$ & $\begin{array}{l}5 \text { days/wk. for } \\
3 \text { wks }\end{array}$ & 2 days/wk. for $8 w k s$ \\
\hline P-value & $\begin{array}{l}\text { TG: } p=0.004 \\
\text { CG: } p=0.004\end{array}$ & $\begin{array}{l}\text { TG: } p<0.05 \\
\text { CG: } p>0.05\end{array}$ & $\begin{array}{l}\text { TGI:p }=0.019 \\
\text { TG2; }=0.001\end{array}$ & TG: $p=0.99$ & TG:P <0.00I & TG:P<0.05 \\
\hline
\end{tabular}

Abbreviations: GI, group one; G2, group two; G3, group three; VAS, visual analog scale; FRI, Functional Rating Index; OLBPD, Ostwestry low back pain disability questioners; ROM, range of motion; PDI, Pain Disability Index; UST, ultrasound therapy; TG, treatment group; CG, control group; OMT, osteopathic manual treatment; PBT, photobiomodulation therapy; wk, week; wks, weeks; TGI, treatment one; TG2, treatment two; RCT, randomized control trial; N, sample size; SD, standard deviation; ES, electrical stimulation; HILT, high-intensity laser therapy; y, year.

concluded that UST was not effective in the treatment of CNSLBP.

\section{Discussion}

This is the primary systematic review as long as our knowledge designs that evaluating the clinical evidence supporting the use of UST based on the highest quality research evidence. The systematic review of randomized controlled trials (RCTs) has been designed to investigate the effectiveness of therapeutic ultrasound on the management of CNSLBP. All six RCTs compare UST with different therapeutics like highintensity laser therapy (HILT), placebo, manipulation, photobiomodulation therapy, and exercise therapy. Although electrotherapeutic modalities and physical agents are commonly used in the treatment of CNSLBP however, still out of the overall studies four of them were found to support their use. $^{7,10,22,27}$ Four of those articles revealed that UST is effective in the management of non-specific chronic LBP in reducing the intensity of pain. Those studies also supported the study conducted by Lewis et a ${ }^{17}$ Prescribed physiotherapy exercises such as general fitness and aerobic exercises, flexibility regimes, stretches, muscle strengthening, and spinal stabilizing exercises were found to be effective in reducing pain in patients with chronic LBP.

In this review, almost all of the included studies on UST can be considered of relatively higher methodological quality. The quality of those articles that include in this study four of them high-quality RCTs, ${ }^{8,10,18,27}$ and two of them are moderate-quality RCTs. ${ }^{7,22}$ According to this review shows UST in four studies great effectiveness in reducing the intensity of pain. For instance, the study had done by Durmus et $\mathrm{al}^{7}$ showed a great improvement in the reduction VAS than exercise only. The maximum treatment sessions that were given in this could be contributed to patient improvement. 
In another two studies, ${ }^{8,18}$ when UST compare with placebo shows the same improvement and ineffective respectively. The possible explanation could be not effective due to the small number of treatment sessions (only six sessions)). Other explanations for ineffectiveness could be for instance the study that was done in Iran 2012 highest dropout recorded. The difference in effectiveness level of UST among studies could due to the variations of mean VAS score running from $46-74 \mathrm{~mm}$. Besides that, all of the studies used different sample size, treatment sessions, and treatment time to do the research. Most of the studies were done without blinding patients or therapists so they were vulnerable to bias and only a few studies had adequate treatment time.

Electrotherapy is one the non-invasive procedure used to treat non-specific chronic LBP, ${ }^{16,23}$ among interferential currents and transcutaneous electrical nerve stimulation are used. $^{9}$ Interferential therapy is used to relieve pain and to increase blood flow to the tissues, ${ }^{1}$ and also more useful than transcutaneous electrical nerve stimulation. ${ }^{31}$ This study was consistent with the study done in turkey by Durmus et $\mathrm{al}^{7}$ comparing ultrasound therapy with electrical stimulation and exercise therapy at the end of the treatment both UST and electrical stimulation was effective in reducing pain than exercise therapy. A research was conducted in 2011 by Fiore et $\mathrm{al}^{10}$ at the University of Foggia Italy participants randomly assigned to take HILT and UST for 3 wks with 15 treatment sessions. The VAS score of the subjects was 7 (median) intensity those who took HILT were reducing from 7 (median) to 3 (median) and took UST 7 (median) to 4 (median) after treatment respectively. At the end of the treatment, both of them were effective in the management of LBP.

This review reveals that ultrasound is usually evaluated as part of a treatment package or in comparison with physiotherapeutic modalities. Generally; the report of two studies stated that UST did not have a beneficial effect on the management of non-specific LBP. However, based on the findings of four similar studies, reported that UST effective in the management of LBP.

\section{Limitations}

In this review only English-language articles were included, other important studies written in another language might be ignored. The majority of studies did not assess evaluate ultrasound therapy as alone, making it somewhat difficult to measure the effectiveness of ultrasound therapy.

\section{Clinical Implication}

The evidence for the effectiveness of UST for nonspecific chronic LBP was observed only in a few groups of separate trials. This review suggests that UST had an important in improving pain, functional activities, and reducing disability. Clinical decision-making will be based on the accessibility of UST when there is constrain modalities.

\section{Conclusion}

In general, in this review, we can conclude that UST has a role in reducing the intensity of pain subjects presented with non-specific chronic LBP. Increased attention should be given to the risks and benefits of long-term use of UST, which more appropriately addresses the realities of managing chronic low back pain. Although in most parts of the world used as routine protocol treatment currently but needed further multi clinical trial studies with larger sample size and better studies with UST only.

\section{Funding}

There is no funding to report.

\section{Disclosure}

The authors report no conflicts of interest for this work.

\section{References}

1. Airaksinen O, Brox JI, Cedraschi C, et al. European guidelines for the management of chronic nonspecific low back pain. Eur Spine J. 2006;15:s192. doi:10.1007/s00586-006-1072-1

2. Allen RJ. Physical agents used in the management of chronic pain by physical therapists. Phys Med Rehabil Clin N Am. 2006;17:315-345. doi:10.1016/j.pmr.2005.12.007

3. Blanger AY. Therapeutic Electrophysical Agents: Evidence Behind Practice. Philadelphia: Lippincott Williams \& Wilkins; 2010.

4. Dagenais S, Caro J, Haldeman S. A systematic review of low back pain cost of illness studies in the United States and internationally. Spine J. 2008;8:8-20. doi:10.1016/j.spinee.2007.10.005

5. de Morton NA. The pedro scale is a valid measure of the methodological quality of clinical trials: a demographic study. Aust $J$ Physiother. 2009;55:129-133. doi:10.1016/S0004-9514(09)70043-1

6. Doğan ŞK, Tur BS, Kurtaiş Y, Atay MB. Comparison of three different approaches in the treatment of chronic low back pain. Clin Rheumatol. 2008;27:873-881. doi:10.1007/s10067-007-0815-7

7. Durmus D, Durmaz Y, Canturk F. Effects of therapeutic ultrasound and electrical stimulation program on pain, trunk muscle strength, disability, walking performance, quality of life, and depression in patients with low back pain: a randomized-controlled trial. Rheumatol Int. 2010;30:901-910. doi:10.1007/s00296-009-1072-7

8. Ebadi S, Ansari NN, Naghdi S, et al. The effect of continuous ultrasound on chronic non-specific low back pain: a single blind placebo-controlled randomized trial. BMC Musculoskelet Disord. 2012;13:192. doi:10.1186/1471-2474-13-192 
9. Facci LM, Nowotny JP, Tormem F, Trevisani VFM. Effects of transcutaneous electrical nerve stimulation (Tens) and interferential currents (Ifc) in patients with nonspecific chronic low back pain: randomized clinical trial. São Paulo Med J. 2011;129:206-216. doi:10.1590/S1516-31802011000400003

10. Fiore P, Panza F, Cassatella G, et al. Short-term effects of high-intensity laser therapy versus ultrasound therapy in the treatment of low back pain: a randomized controlled trial. Eur J Phys Rehabil Med. 2011;47:367-373.

11. Guyatt G, Oxman AD, Akl EA, et al. Grade guidelines: 1 . Introduction-grade evidence profiles and summary of findings tables. J Clin Epidemiol. 2011;64:383-394. doi:10.1016/j.jclinepi.20 10.04.026

12. Hirano K, Imagama S, Hasegawa Y, Ito Z, Muramoto A, Ishiguro N. Impact of low back pain, knee pain, and timed up-and-go test on quality of life in community-living people. $J$ Orthop Sci. 2014;19:164-171. doi:10.1007/s00776-013-0476-0

13. Huang Z, Ma J, Chen J, Shen B, Pei F, Kraus VB. The effectiveness of low-level laser therapy for nonspecific chronic low back pain: a systematic review and meta-analysis. Arthritis Res Ther. 2015;17:1-8. doi:10.1186/s13075-015-0882-0

14. Koes BW, van Tulder M, Lin C-WC, Macedo LG, McAuley J, Maher C. An updated overview of clinical guidelines for the management of non-specific low back pain in primary care. Eur Spine J. 2010;19:2075-2094. doi:10.1007/s00586-010-1502-y

15. Krismer M, Van Tulder M. Low back pain (non-specific). Best Pract Res Clin Rheumatol. 2007;21:77-91. doi:10.1016/j.berh.2006.08.004

16. Ladeira CE, Samuel Cheng M, Hill CJ. Physical therapists treatment choices for non-specific low back pain in florida: an electronic survey. J Man Manip Ther. 2015;23:109-118. doi:10.1179/20426 18613Y.0000000065

17. Lewis A, Morris ME, Walsh C. Are physiotherapy exercises effective in reducing chronic low back pain? Phys Ther Rev. 2008;13:37-44. doi: $10.1179 / 174328808 X 252000$

18. Licciardone JC, Minotti DE, Gatchel RJ, Kearns CM, Singh KP. Osteopathic manual treatment and ultrasound therapy for chronic low back pain: a randomized controlled trial. Ann Fam Med. 2013;11:122-129. doi:10.1370/afm.1468

19. Maher CG, Sherrington C, Herbert RD, Moseley AM, Elkins M. Reliability of the pedro scale for rating quality of randomized controlled trials. Phys Ther. 2003;83:713-721. doi:10.1093/ptj/83.8.713

20. Moher D, Shamseer L, Clarke M, et al. Preferred reporting items for systematic review and meta-analysis protocols (Prisma-P) 2015 statement. Syst Rev. 2015;4:1. doi:10.1186/2046-4053-4-1

21. Moher D, Liberati A, Tetzlaff J, Altman DG; Prisma Group. Preferred reporting items for systematic reviews and meta-analyses: the prisma statement. PLoS Med. 2009;6:e1000097. doi:10.1371/journal.pmed.1000097
22. Mohseni-Bandpei MA, Critchley J, Staunton T, Richardson B. A prospective randomised controlled trial of spinal manipulation and ultrasound in the treatment of chronic low back pain. Physiotherapy. 2006;92:34-42. doi:10.1016/j.physio.2005.05.005

23. Poitras S, Blais R, Swaine B, Rossignol M. Management of work-related low back pain: a population-based survey of physical therapists. Phys Ther. 2005;85:1168-1181. doi:10.1093/ptj/85.11. 1168

24. Rajfur J, Pasternok M, Rajfur K, et al. Efficacy of selected electrical therapies on chronic low back pain: a comparative clinical pilot study. Med Sci Mon. 2017;23:85.

25. Robertson VJ, Low J, Ward A, Reed A. Electrotherapy Explained: Principles and Practice. Elsevier Health Sciences; 2006.

26. Shanks P, Curran M, Fletcher P, Thompson R. The effectiveness of therapeutic ultrasound for musculoskeletal conditions of the lower limb: a literature review. The Foot. 2010;20:133-139. doi:10.1016/j. foot.2010.09.006

27. Tantawy SA, Abdelbasset WK, Kamel DM, Alrawaili SM, Alsubaie SF. Laser photobiomodulation is more effective than ultrasound therapy in patients with chronic nonspecific low back pain: a comparative study. Lasers Med Sci. 2019;34:793-800. doi:10.1007/ s10103-018-2665-8

28. Taradaj J, Ozon M, Dymarek R, Bolach B, Walewicz K, Rosińczuk J. Impact of selected magnetic fields on the therapeutic effect in patients with lumbar discopathy: a prospective, randomized, single-blinded, and placebo-controlled clinical trial. Adv Clin Exp Med. 2018;27:649-666. doi:10.17219/acem/68690

29. Tugay N, Akbayrak T, Demirtürk F, et al. Effectiveness of transcutaneous electrical nerve stimulation and interferential current in primary dysmenorrhea. Pain Med. 2007;8:295-300. doi:10.1111/ j.1526-4637.2007.00308.x

30. Walewicz K, Taradaj J, Dobrzyński M, et al. Effect of radial extracorporeal shock wave therapy on pain intensity, functional efficiency, and postural control parameters in patients with chronic low back pain: a randomized clinical trial. J Clin Med. 2020;9:568. doi:10. 3390/jcm9020568

31. Ward AR, Lucas-Toumbourou S. Lowering of sensory, motor, and pain-tolerance thresholds with burst duration using kilohertz-frequency alternating current electric stimulation. Arch Phys Med Rehabil. 2007;88:1036-1041. doi:10.1016/j.apmr.2007. 04.009

32. Zambito A, Bianchini D, Gatti D, Viapiana O, Rossini M, Adami S. Interferential and horizontal therapies in chronic low back pain: a randomized, double blind, clinical study. Clin Exp Rheumatol. 2006;24:534-539.
Journal of Pain Research

\section{Publish your work in this journal}

The Journal of Pain Research is an international, peer reviewed, open access, online journal that welcomes laboratory and clinical findings in the fields of pain research and the prevention and management of pain. Original research, reviews, symposium reports, hypothesis formation and commentaries are all considered for publication. The manuscript

Submit your manuscript here: https://www.dovepress.com/journal-of-pain-research-journal management system is completely online and includes a very quick and fair peer-review system, which is all easy to use. Visit http:// www.dovepress.com/testimonials.php to read real quotes from published authors. 